DOI: https://doi.org/10.35699/2237-5864.2018.2393

\title{
RODA DE CONVERSA SOBRE AS PRÁTICAS DE EDUCAÇÃO EM SAÚDE COM UM GRUPO DE ACADÊMICOS DO CURSO DE MEDICINA
}

\author{
Alessandra Regina Müller Germani ${ }^{1}$ \\ Lissandra Glusczak ${ }^{1}$ \\ Silvane Nenê Portela ${ }^{1}$ \\ Maristela Vilas Boas Fratucci²
}

\section{RESUMO}

O presente artigo apresenta um relato de experiência sobre a realização de um processo educativo-reflexivo, por meio de uma roda de conversa, sobre as práticas de educação em saúde, com acadêmicos do curso de Medicina da Universidade Federal da Fronteira Sul. A roda de conversa ocorreu no auditório do campus Passo Fundo, sendo dividida em quatro passos: Conhecendo o grupo, Conceituando educação em saúde, Contextualizando educação em saúde e Avaliando o encontro. Ao final, pudemos evidenciar que as manifestações dos acadêmicos estavam em sintonia com os pressupostos de uma educação em saúde libertadora/ emancipatória, e que um dos grandes desafios colocados por eles se refere à produção de mais espaços dialógicos nos serviços de saúde, que estejam focados nos princípios do acolhimento e da humanização da assistência, promovendo, assim, o fortalecimento da articulação entre ensino, serviço e comunidade.

Palavras-chave: Processo educativo-reflexivo. Roda de conversa. Educação em saúde. Integração ensino-serviço-comunidade.

\footnotetext{
${ }^{1}$ Universidade Federal da Fronteira Sul, Passo Fundo, RS, Brasil.

2 Universidade Federal do Rio Grande do Sul, Porto Alegre, RS, Brasil.
} 


\title{
CONVERSATION CIRCLE ON THE PRACTICES OF HEALTH EDUCATION WITH A GROUP OF ACADEMICS OF THE MEDICINE COURSE
}

\author{
Alessandra Regina Müller Germani \\ Lissandra Glusczak \\ Silvane Nenê Portela \\ Maristela Vilas Boas Fratucci
}

\begin{abstract}
This article presents an experience report about the realization of an educative-reflective process, through a conversation circle, about health education practices, with academics of the Medicine Course, Federal University of Southern Border. The talk round took place in the Passo Fundo Campus Auditorium, being divided into four steps: Knowing the group, Conceptualizing health education, Contextualizing health education and Evaluating the meeting. In the end we showed that the manifestations of the academics were in tune with the assumptions of a liberating/emancipatory health education and that one of the great challenges posed by them is the production of more dialogic spaces in health services, which are focused on the principles of welcoming and humanizing assistance, thus promoting the strengthening of the articulation between teaching, service and community.
\end{abstract}

Keywords: Educational-reflective process. Conversation circle. Health education. Teachingservice-community integration. 


\section{INTRODUÇÃO}

As práticas de educação em saúde no Brasil reúnem diferentes características, acompanhando a conjuntura econômica, política e social de cada período histórico. Assim, elas surgem em meados do século XX, ligadas principalmente ao combate de epidemias e ao desenvolvimento de campanhas sanitárias, tendo em vista que as doenças geravam problemas às exportações, principalmente a do café. A população, de uma maneira geral, naquele período, era desconsiderada, e as práticas educativas desenvolvidas pelos profissionais da área da saúde pautavam-se em normatizações e em processos impositivos de mudanças comportamentais, reflexo dos aprendizados recebidos na academia (FINKELMAN, 2002).

Nesse sentido, Vasconcelos (1997) refere que a educação em saúde tradicional pode ser entendida como uma maneira de fazer as pessoas do povo, a população em geral, mudar alguns comportamentos, considerados prejudiciais à saúde, sendo as informações para isso transmitidas de forma verticalizada/impositiva pelos profissionais de saúde, tidos nesse contexto como detentores do saber, sem se incluir a participação das pessoas nesse processo.

Como essa forma de atuar não estava de acordo com a realidade vivida pela maioria da população, no início do século XXI, segundo Lima e Costa (2005), descortina-se um novo cenário, mais alentador, para a educação em saúde. Evidencia-se nesse momento uma preocupação dos profissionais da saúde em adotar posturas diferentes das até então assumidas, na perspectiva de superar a desigualdade e o distanciamento existente entre os serviços de saúde, a população e as universidades.

Dessa maneira, a educação em saúde passa a se configurar como um caminho para essa aproximação entre os serviços de saúde, a população e as universidades, sendo que, para isso, precisa ser entendida como um processo pautado no diálogo e na troca de saberes, num verdadeiro intercâmbio entre o saber popular e o científico, em que cada um dos atores envolvidos tem muito a ensinar e a aprender (VASCONCELOS, 1997).

Em 2013, é lançada a Política Nacional de Educação Popular em Saúde, propondo que o desenvolvimento de ações de saúde seja pautado numa relação dialógica entre profissionais de saúde e comunidade, levando em consideração as diferentes experiências sociais, para potencializar o diálogo, a produção de conhecimento e as diferentes formas de intervenção na luta por saúde. Esse processo, que alia os saberes científico e popular no desenvolvimento 
das ações de saúde, serve para fortalecer o entendimento de que saúde é um direito, devendo ser assegurado por ações governamentais e participação consciente da comunidade (BRASIL, 2013).

A realização de uma educação em saúde, nessa perspectiva, que de fato atenda às necessidades da população, remete-nos à concepção problematizadora proposta por Paulo Freire. A educação problematizadora permite que os educandos passem de receptores de informações para um estágio crítico do processo educacional deles. Existe uma relação dialógica entre o educador e o educando e vice-versa. Assim, a população torna-se consciente do papel que exerce na sociedade e busca, por meio de ferramentas próprias, autonomia frente à resolução dos problemas que enfrenta.

Sensibilizadas por essas questões, entendemos a pertinência de promover, por ocasião do trabalho de conclusão do curso de Especialização em Docência na Saúde, promovido pela Universidade Federal do Rio Grande do Sul (UFRGS) e pelo Ministério da Saúde, um processo educativo-reflexivo, por meio de uma roda de conversa com acadêmicos do curso de Medicina da Universidade Federal da Fronteira Sul (UFFS), campus Passo Fundo/RS, sobre as práticas de educação em saúde, na perspectiva de ser esse um espaço dialógico/problematizador capaz de viabilizar a identificação de diferentes compreensões e vivências acerca dessas práticas, contribuindo, assim, para o fortalecimento da integração ensino-serviço-comunidade.

\section{PERCURSO METODOLÓGICO}

\section{Cenário e atores da roda de conversa}

A UFFS, campus Passo Fundo/RS, conta com um curso de Medicina que integra o Plano Nacional de Expansão dos Cursos de Medicina, instituído pela Portaria do MEC n 109, de 5 de junho de 2012, e cujas atividades acadêmicas se iniciaram em 17 de setembro de 2013. Atualmente, o curso conta com 114 discentes matriculados, 28 docentes e 23 técnicos administrativos concursados. O projeto pedagógico do curso segue os preceitos da Constituição Federal Brasileira no que se refere à reorientação da formação profissional na área da saúde, bem como as Diretrizes Curriculares Nacionais do Curso de Graduação em Medicina, e as orientações do Ministério da Educação que acompanham o Plano de Expansão da Educação em Saúde, sobretudo as de fortalecimento do Sistema Único de Saúde (SUS). 
Portanto, o processo formativo do curso visa preparar os futuros médicos para enfrentar os desafios atuais do SUS no Brasil e da necessidade de permanência e fixação de médicos em áreas onde há carência desses profissionais. Para isso, um dos pontos fortes desse processo formativo é a Imersão/Vivência no SUS, que se refere à participação dos acadêmicos, do primeiro ao oitavo semestre, nas diferentes ações que são desenvolvidas tanto no âmbito dos serviços de saúde (Atenção Básica, Especializada e Hospitalar) quanto nas comunidades, fortalecendo e qualificando a formação profissional desses estudantes.

Nesse contexto, a cooperação entre a universidade, os serviços e a comunidade é essencial, porque é no convívio com a realidade social, por meio de uma prática de ensino em novos cenários, e o trabalho com os problemas reais que colocam professores, acadêmicos e comunidade em constante movimento, criando novos espaços para debate, estimulando a superação de dificuldades, além de oportunizar a responsabilização social.

Dessa forma, a roda de conversa foi realizada no auditório do campus Passo Fundo/RS, com os acadêmicos do curso de Medicina, que, mediante convite em sala de aula, aceitaram participar da atividade, totalizando cinco acadêmicos. Os acadêmicos são do Rio Grande do Sul e um de São Paulo. Alguns já cursavam outros cursos antes da Medicina, e um dos participantes é integrante do movimento social de criação da UFFS ${ }^{3}$. Todos estavam cursando disciplinas do segundo semestre do curso de Medicina, envolvidos com as aulas práticas de Saúde Coletiva, chamada de Imersão/Vivência no SUS, nos municípios de Passo Fundo, Pontão, Sertão, Ernestina, Marau e Água Santa. A roda de conversa foi realizada no mês de agosto de 2015, no turno da tarde, com duração de 5 horas/aula, sendo o processo conduzido por uma professora de Saúde Coletiva.

\footnotetext{
${ }^{3}$ Movimento Pró Universidade - grupo que iniciou em 2005 o debate sobre a constituição de uma instituição de educação superior e que resultou na UFFS. Nos três estados da região Sul do país, integraram esse movimento segmentos como a Federação dos Trabalhadores na Agricultura Familiar da Região Sul (FETRAF-SUL), a Via Campesina, o Fórum da Mesorregião, a Central Única dos Trabalhadores (CUT), igrejas, movimento estudantil, associações de prefeitos, vereadores, deputados estaduais e federais, senadores.
} 


\section{Plano de ação}

O processo educativo-reflexivo acerca das práticas de educação em saúde ocorreu por meio do desenvolvimento de uma roda de conversa, dividida em quatro passos distintos, os quais são apresentados no quadro a seguir.

Quadro 1 - Passos da roda de conversa sobre educação em saúde

\begin{tabular}{lcl}
\hline & Passos & \multicolumn{1}{c}{ Descrição } \\
\hline Primeiro passo & Conhecendo o grupo & $\begin{array}{l}\text { Apresentação pessoal e das expectativas em } \\
\text { relação à roda de conversa. }\end{array}$ \\
Segundo passo & $\begin{array}{l}\text { Conceituando educação } \\
\text { em saúde }\end{array}$ & $\begin{array}{l}\text { Realização de dinâmica na qual cada participante } \\
\text { conceituou educação em saúde e socializou o } \\
\text { conceito com o grupo. }\end{array}$ \\
Qunceiro passo & $\begin{array}{l}\text { Contextualizando edu- } \\
\text { cação em saúde }\end{array}$ & $\begin{array}{l}\text { Contextualização das apresentaçães, fazendo um } \\
\text { paralelo entre a educação em saúde tradicional e } \\
\text { a problematizadora/emancipatória. }\end{array}$ \\
& Avaliando o encontro & $\begin{array}{l}\text { Por meio de manifestaçães verbais, os par- } \\
\text { ticipantes avaliaram a realização da roda de } \\
\text { conversa. }\end{array}$ \\
\hline
\end{tabular}

Fonte: elaborado pelas autoras, 2017.

\section{RELATO E DISCUSSÃO DA ATIVIDADE}

\section{Primeiro passo - Conhecendo o grupo}

No primeiro passo da roda de conversa, promovemos a apresentação pessoal dos participantes, bem como das expectativas deles com relação ao processo educativo-reflexivo sobre educação em saúde, com a finalidade de acolhê-los e prepará-los para os demais passos do encontro. Esse momento é essencial, pois os participantes se reconhecem como um grupo. Dessa forma, o grupo constrói um clima emocional próprio, por meio das relações entre os seus membros. A dimensão em que o grupo opera compreende os movimentos do conjunto como um todo, nos diferentes níveis de interação (MOSCOVICl, 1999). 
De acordo com Moscovici (1999), com relação ao nível socioemocional, o grupo ocorre em três dimensões, quais sejam: intrapessoal, interpessoal e de grupo. A dimensão intrapessoal se refere às relações, à motivação e à ideologia da pessoa. É decisiva na interação com os outros. A interpessoal desenvolve-se em decorrência do processo de interação entre os membros e pode assumir formas afetuosas e de cooperação ou formas conflitivas, competitivas e de aparente cordialidade. Desta forma, o grupo se estabelece em um clima emocional próprio e compreende os movimentos do conjunto das diferentes formas de interação.

Para isso, o autor reforça que a comunicação entre os membros do grupo deve acontecer de forma verdadeira, com estímulo a opiniões divergentes. As expectativas e objetivos devem ser compartilhados por meio do respeito e da cooperação. Deve haver investimento constante do grupo no próprio desenvolvimento. E a confiança, nesse processo, é um fator determinante, que possibilita assumir riscos e, assim, atingir os resultados previstos.

Partindo do exposto acima, cada participante foi estimulado a se apresentar relatando nome, cidade de origem, motivo que o levou a cursar Medicina, experiências nas atividades de Imersão/Vivência no SUS e expectativas com relação ao debate sobre a temática educação em saúde. Evidenciamos que um ponto comum dos participantes refere-se à vontade e à curiosidade de aprender mais sobre a temática, pois, já nas primeiras experiências da Imersão/ Vivência no SUS, eles identificaram fragilidades nos municípios. Os participantes também compreendem que a educação em saúde contribui significativamente para a consolidação do SUS.

Na oportunidade, apresentamos o objetivo da roda de conversa e também esclarecemos aos participantes o nosso papel como mediadoras desse processo, responsáveis pela condução do grupo à reflexão, à análise e à síntese dos conhecimentos. Hurtado (1993) refere que o mediador deve estar atento à dinâmica que desenvolve o próprio grupo, para mantêlo animado e ativo, na perspectiva de minimizar situações de cansaço, tédio e tensão nos encontros.

\section{Segundo passo - Conceituando educação em saúde}

Para Freire (1987), os homens não são seres vazios que precisam ser "enchidos" de conteúdos, mas, sim, sujeitos que possuem uma consciência, que possuem uma intenção. Sendo assim, o homem é capaz de problematizar o mundo, partindo da consciência que possui deste. Com 
isso, a proposta de educação ultrapassa os limites de uma teoria, passando a ser entendida como forma de compreender o mundo, refletir sobre ele e transformar a realidade a partir de uma ação consciente.

Nesse sentido, no segundo passo da roda de conversa, foram distribuídos a cada participante uma folha de papel sulfite e uma caneta, para que individualmente elaborasse uma ou mais frases representando as concepções que tem sobre educação em saúde. Dando continuidade, cada participante fez a leitura e o comentário da concepção que anotou sobre educação em saúde. Vários elementos foram trazidos pelos acadêmicos, fruto das experiências pessoais e das atividades de Imersão/Vivência no SUS, na perspectiva da superação das práticas de educação em saúde tradicionais, e puderam ser evidenciados nas seguintes manifestações:

... é criar uma consciência sobre a saúde e o bem estar de modo global no indivíduo e no coletivo. É ter clareza sobre saúde, doença, ser saudável, qualidade de vida e prevenção de males ao indivíduo... (Participante 4).

... orientar, informar os usuários do sistema e redes de saúde para que se tornem protagonistas e responsáveis pela sua saúde, assim como os trabalhadores e gestores do sistema (Participante 3 ).

A fala da Participante 3 nos remete à imagem do quadrilátero da formação para a área da saúde, proposto por Ceccim e Feuerwerker (2004). Segundo os autores, a formação quadrilátera propõe construir e organizar uma educação responsável por processos interativos e de ação na realidade, para operar mudanças, mobilizar caminhos, convocar protagonismos e detectar a paisagem interativa e móvel de indivíduos, coletivos e instituições.

Assim, a incorporação de uma proposta formativa com esse viés mostra-se cada vez mais necessária, representando um ato de criar e de transformar a realidade, de reverter o modelo de atenção à saúde desenvolvido no país e, assim, contribuir para a consolidação dos princípios e diretrizes do SUS. A fala do Participante 1 retrata esse aspecto quando diz que:

A partir de estudos, pesquisas e análises são traçados panoramas do modelo atual de saúde, bem como suas falhas e pontos positivos. Com isso, é possível melhorar o modelo de atendimento e, até mesmo, o panorama atual de saúde (Participante 1).

O SUS configura-se uma conquista expressa na forma da lei, no entanto ainda evidenciamos um distanciamento com relação à concretização do sistema na prática. Segundo Passos e 
Benevides (2004), é a ideia de "único", encontrada no SUS, que indica o tipo de projeto e, sobretudo, a forma de implantação. Para tanto, é necessário conectar diferentes atores no processo de produção de saúde. O SUS não se sustenta numa mera abstração, ele se efetiva por meio da mudança do modelo de atenção à saúde.

$\mathrm{Na}$ esteira desse debate, sobre educação em saúde e a necessidade da reversão do modelo assistencial vigente, o Participante 5 traz à tona outro elemento essencial às práticas educativas, a humanização. Para ele, a educação em saúde:

... deve ser humanizada para que possamos entender todos os aspectos dos nossos usuários, sejam eles os culturais, do meio em que vivem, familiares, etc... (Participante 5).

Sobre a humanização, Passos e Benevides (2004) referem que deve se constituir como uma vertente orgânica do SUS, por meio do estímulo a um processo contínuo de contratação, de pactuação, que se efetiva a partir do aquecimento das redes e do fortalecimento dos coletivos.

A humanização como política transversal do SUS supõe necessariamente ultrapassar as fronteiras, muitas vezes rígidas, dos diferentes núcleos de saber/poder que se ocupam da produção da saúde. Ao assumir a temática da humanização como transversal garante-se o caráter questionador das verticalidades pelas quais estamos, na saúde, sempre em risco de nos ver capturados.

\section{Terceiro passo - Contextualizando educação em saúde}

Segundo Freire (2000), o processo de mudança de percepção se dá por meio da análise da realidade, de se questionar o que se apresenta, levando os participantes à criticidade, a posições indagadoras, inquietas e criadoras. Dessa forma, passamos para o terceiro passo da roda de conversa, momento em que os participantes foram estimulados/instigados a refletirem sobre as concepções de educação em saúde apresentadas/vivenciadas por eles.

Para tanto, utilizamos como suporte teórico os materiais disponibilizados no decorrer da especialização, bem como traçamos um paralelo, a partir dos estudos de Vasconcelos (1997), entre a educação em saúde tradicional e a problematizadora/emancipatória. Além disso, com o intuito de enriquecer esse momento de reflexão, relatamos nossas experiências pessoais/ 
profissionais de implementação das práticas educativas em saúde, tanto no ambiente hospitalar quanto na atenção básica.

Assim, partindo da reflexão sobre a realidade vivenciada, os acadêmicos puderam descobrir e/ou entender questões/aspectos velados, que não conseguimos perceber no cotidiano. Eles enfatizaram que, para a realização da educação em saúde, deve-se primeiramente partir da realidade da população, para posteriormente se elaborar um plano que contemple ações que venham contribuir para a melhoria da qualidade de vida dessa população.

Nesse sentido, Vasconcelos (2001) refere que a educação em saúde deixa de ser uma mera atividade realizada nos serviços para ser algo que atinge e reorienta a diversidade de práticas realizadas, passando, assim, a ser entendida como um instrumento de construção da participação popular nos serviços de saúde e, ao mesmo tempo, de aprofundamento da intervenção da ciência na vida cotidiana da população, articulando plenamente o saber popular ao científico.

Para isso, torna-se necessário redefinir os processos formativos nas universidades, para que contemplem essa forma de se estruturar/promover a educação em saúde, pois ainda identificamos, no cotidiano dos serviços, práticas alicerçadas no modelo tradicional de educação em saúde. Nesse modelo tradicional, a transmissão dos conhecimentos se dá de forma verticalizada, na qual o educador é o detentor do saber e o educando, um mero depósito a ser preenchido.

\section{Quarto passo - Avaliando o encontro}

O quarto passo compreendeu um momento de avaliação com os participantes sobre a roda de conversa. Por meio de manifestações verbais, eles destacaram a relevância de estarem discutindo e refletindo sobre as diferentes experiências e concepções de educação em saúde, bem como da aproximação com vários autores que abordam a temática.

Esse momento de troca de conhecimentos proporcionou novos olhares/conhecimentos sobre as práticas de educação em saúde historicamente instituídas no nosso país e a clareza sobre os desafios a serem assumidos para a realização de práticas sintonizadas com os princípios e diretrizes do SUS. 
Sobre a metodologia problematizadora, Freire (1987) refere que o momento de ida e volta, do abstrato ao concreto, que se dá na análise de uma situação codificada - no nosso caso, sobre a educação em saúde -, se bem feita a decodificação, conduz à superação da abstração com a percepção crítica do concreto.

Os participantes ainda mencionaram que espaços dessa natureza deveriam ser permanentemente propiciados não só aos acadêmicos, mas também aos demais envolvidos com a realização das práticas educativas na saúde, tanto no âmbito do ensino quanto no da atenção à saúde, no da gestão e no da participação social, possibilitando a socialização de conhecimentos e consequentemente o enriquecimento dessas práticas.

\section{CONSIDERAÇÕES FINAIS}

Portanto, o desenvolvimento do processo educativo-reflexivo, por meio de uma roda de conversa com acadêmicos do curso de Medicina sobre as práticas de educação em saúde, permitiu-nos perceber que, de maneira geral, as manifestações dos acadêmicos estavam em sintonia com os pressupostos de uma educação em saúde problematizadora/emancipatória, que permite a troca de conhecimento e, consequentemente, a construção a partir das experiências vivenciadas. Evidencia-se, assim, que um dos grandes desafios para se trabalhar com a educação em saúde é o de produzir diálogos, focando-se nos princípios do acolhimento e da humanização da assistência e, assim, promovendo a articulação entre o ensino e a atenção à saúde na gestão do SUS e na participação social.

Dessa forma, entendemos que o processo educativo-reflexivo, apesar de ocorrer em um dia, foi intenso e profundo, gerando encaminhamentos ao curso de Medicina. Um deles é a institucionalização das rodas de conversas, para tratar de temas diversos com os diferentes segmentos, acadêmicos, profissionais dos serviços de saúde, conselheiros de saúde, dentre outros, por meio da extensão universitária. Outro encaminhamento é a produção de um documento, que será enviado ao Núcleo Docente Estruturante (NDE) do curso de Medicina, solicitando a inclusão das rodas de conversa como um componente curricular optativo.

Além disso, os diferentes conhecimentos apreendidos durante as disciplinas do curso de especialização deram suporte para a realização da roda de conversa e para as nossas práticas como docentes. Tivemos o cuidado de propiciar um espaço dialógico/problematizador, onde, por meio das trocas de conhecimentos, pudemos refletir sobre a realidade atual das práticas 
educativas em saúde, bem como, num esforço coletivo, traçar possíveis alternativas, quem sabe, soluções, aos problemas levantados.

\section{REFERÊNCIAS}

BRASIL. Portaria SESu/MEC n 109, de 5 de junho de 2012. Dispõe sobre a expansão de vagas em cursos de Medicina e criação de novos cursos nas Universidades Federais. Diário Oficial da União, Poder Executivo, Brasília, DF, 8 jun. 2012.

BRASIL. Portaria $n^{\circ}$ 2.761, de 19 de novembro de 2013. Institui a Política Nacional de Educação Popular em Saúde no âmbito do Sistema Único de Saúde (PNEPS-SUS). Diário Oficial da União, Poder Executivo, Brasília, DF, 20 nov. 2013.

CECCIM, Ricardo B.; FEUERWERKER, Laura C. M. O quadrilátero da formação para a área da saúde: ensino, gestão, atenção e controle social. Physis: Rev. de Saúde Coletiva, Rio de Janeiro, v. 14, n. 1, p. 41-65, 2004.

FINKELMAN, Jacobo. Caminhos da saúde pública no Brasil. Rio de Janeiro: Editora FIOCRUZ, 2002.

FREIRE, Paulo. Pedagogia do oprimido. 17. ed. Rio de Janeiro: Paz e Terra, 1987.

FREIRE, Paulo. Política e educação. 4. ed. São Paulo: Cortez, 2000.

HURTADO, Carlos N. Educar para transformar, transformar para educar: comunicação e educação popular. Petrópolis, RJ: Vozes, 1993.

LIMA, Keite A.; COSTA, Fátima N. A. Educação em saúde e pesquisa qualitativa: relações possíveis. Alimentos e Nutrição, Araraquara, UNESP, v. 16, n. 1, p. 33-38, jan./mar. 2005.

MOSCOVICl, Fela. Equipes dão certo: a multiplicação do talento humano. 5. ed. Rio de Janeiro: José Olympio, 1999.

PASSOS, Eduardo; BENEVIDES, Regina. Clínica, política e as modulações do capitalismo. Lugar Comum, n. 19-20, p. 159-171, jan./jun. 2004.

VASCONCELOS, Eymard M. Educação popular nos serviços de Saúde. 3. ed. São Paulo: Hucitec, 1997.

VASCONCELOS, Eymard M. Educação popular e a atenção à saúde da família. 2. ed. São Paulo: Sobral, Hucitec-Uvas, 2001. 


\section{Alessandra Regina Müller Germani}

Graduação em Enfermagem pela Universidade Federal de Santa Maria (UFSM), 1999, mestrado em Enfermagem pela Universidade Federal de Santa Catarina (UFSC), 2002. Especialização em Docência na Saúde pela Universidade Federal do Rio Grande do SUI (UFRGS), 2015. Doutoranda no Programa de Pós-Graduação em Extensão Rural (PPGEXR) pela UFSM (2015 em diante). alessandragermani@hotmail.com

\section{Lissandra Glusczak}

Graduação em Farmácia - Análises Clínicas, pela Universidade de Cruz Alta (UNICRUZ), 2000, e doutorado em Ciências Biológicas - na área de Bioquímica Toxicológica -, pela UFSM (2008). Especialização em Docência na Saúde pela UFRGS (2015).

lissandra.glusczak@uffs.edu.br

\section{Silvane Nenê Portela}

Graduação em Medicina pela Universidade de Passo Fundo (1996), residência médica em Ginecologia e Obstetrícia (1996-1999). Título de especialista em Ginecologia e Obstetrícia (1999). Título de habilitação Advanced Life Support in Obstetrics Course (ALSO), 2001. Mestrado em Ciências da Saúde pela Universidade Federal Ciências da Saúde de Porto Alegre (2012). Especialização em Docência na Saúde pela UFRGS (2015).

silvane.portela@uffs.edu.br

\section{Maristela Vilas Boas Fratucci}

Graduação em Odontologia pelo Instituto Metodista de Ensino Superior (1985). Cirurgiãdentista sanitarista e mestre pela Faculdade de Saúde Pública da Universidade de São Paulo (USP), 2000. Doutora na Faculdade de Odontologia da USP, no programa de Ciências Odontológicas. Tutora na especialização em Docência na Saúde da UFRGS (2015). acmaris@gmail.com 